\title{
Effects of the Addition of Mosapride to Gastroesophageal Reflux Disease Patients on Proton Pump Inhibitor: A Prospective Randomized, Double-blind Study
}

\author{
Hyun Chul Lim, ${ }^{1}$ Jie-Hyun Kim, ${ }^{1}$ Young Hoon Youn, ${ }^{1}$ Eun Hee Lee, ${ }^{2}$ Byung Keon Lee ${ }^{2}$ and Hyojin Park ${ }^{1 *}$ \\ ${ }^{1}$ Department of Internal Medicine, Gangnam Severance Hospital, Yonsei University College of Medicine, Seoul, Korea; and ${ }^{2}$ Research Center, \\ Green Cross Corporation, Yongin, Gyeonggi-do, Korea
}

\section{Background/Aims}

Proton pump inhibitors (PPIs) which are the most effective agents for the treatment of gastroesophageal reflux disease (GERD), have been known to delay gastric emptying. Mosapride has been used as prokinetics by accelerating gastric emptying. We evaluated the efficacy of mosapride to prevent PPI-induced delayed gastric emptying in a prospective randomized, double-blind and placebo-controlled trial.

\section{Methods}

Thirty patients who were diagnosed as GERD and had normal gastric emptying were included in this study. PPI monotherapy group was treated with placebo drug in addition to pantoprazole and PPI plus mosapride group was treated with mosapride in addition to pantoprazole for 8 weeks. Gastric emptying scan and questionnaires about GERD and dyspeptic symptoms were assessed by scoring before and after treatment. To evaluate the changes of gastrointestinal endocrine hormones by PPI which are associated gastric acid secretion and gastric motility, fasting plasma gastrin and cholecystokinin were taken at weeks 0 and 8 .

\section{Results}

Half gastric emptying time was increased $(P=0.023)$ in PPI monotherapy group, and there were no significant changes in PPI plus mosapride group. Plasma gastrin level increased in PPI monotherpay group $(P=0.028)$ and there were no significant changes in PPI plus mosapride group. Plasma cholecystokinin level was not changed after treatment in both groups. GERD symptoms were improved after treatment in both groups, and postprandial bloating and nausea were improved in PPI plus mosapride group.

\section{Conclusions}

Mosapride showed to be effective in preventing delayed gastric emptying and the increase in plasma gastrin level induced by PPI treatment, but did not show prominent clinical symptom improvements.

(J Neurogastroenterol Motil 2013;19:495-502)

\section{Key Words}

Gastric emptying; Gastroesophageal reflux; Mosapride; Proton pump inhibitors

Received: January 28, 2013 Revised: June 24, 2013 Accepted: June 25, 2013

(c) This is an Open Access article distributed under the terms of the Creative Commons Attribution Non-Commercial License (http://creativecommons. org/licenses/by-nc/3.0) which permits unrestricted non-commercial use, distribution, and reproduction in any medium, provided the original work is properly cited.

${ }^{*}$ Correspondence: Hyojin Park, MD, PhD

Department of Internal Medicine, Gangnam Severance Hospital, Yonsei University College of Medicine, 712, Eonju-ro, Gangnam-gu, Seoul 135-720, Korea

Tel: +82-2-2019-3310, Fax: +82-2-3463-3882, E-mail: hjpark21@yuhs.ac

Financial support: This study was supported by the Daewoong Pharm Co. Ltd, Seoul Korea.

Conflicts of interest: None.

Author contributions: Hyun Chul Lim analyzed data and wrote the manuscript. Hyojin Park designed organized and mediated the present study and supervised the manuscript. Jie-Hyun Kim, Young Hoon Youn, Eun Hee Lee and Byung Keon Lee revised the manuscript and advised design of study. 


\section{Introduction}

Gastroesophageal reflux disease (GERD) is one of the most common disease characterized by reflux symptoms like heartburn and acid regurgitation. ${ }^{1,2}$ The treatment of GERD is based on anti-secretory compounds, including histamine H2-receptor antagonists $\left(\mathrm{H}_{2} \mathrm{RAs}\right)$ and proton pump inhibitors (PPIs). ${ }^{3}$ PPIs are widely used due to providing more long-lasting symptom relief with esophageal healing than any other available drugs including $\mathrm{H}_{2} \mathrm{RAs}$, currently. ${ }^{4}$

However, PPIs have been known to delay gastric emptying from $15 \%$ to $40 \% .^{5-7}$ The mechanisms for delayed gastric emptying induced by PPIs were discussed as decreased gastric acid which resulted in inadequate hydrolysis of food, enhanced secretion of gastrin, and decreased fluid secretion into the stomach. ${ }^{6,8,9}$ Delayed gastric emptying could influence functional gastrointestinal disorders including gastroesophageal reflux disease, peptic ulcer disease and functional dyspepsia. ${ }^{10-12}$

Mosapride is a selective 5-hydroxytryptamine type 4 (5$\mathrm{HT}_{4}$ ) receptor agonist and has been used in patients with upper gastrointestinal disorders by shortening gastric emptying in healthy volunteers and gastroparesis. 13,14

Gastrin and cholecystokinin (CCK) are homologous gastrointestinal endocrine hormones which are known to regulate gastric acid secretion, gastric emptying, growth of gastric mucosa and intestinal motility in upper gastrointestinal tract. ${ }^{15-17}$

We conducted a prospective randomized, double blind and placebo-controlled clinical trial to evaluate the hypothesis that mosapride can normalize or prevent PPI-induced delayed gastric emptying, and we evaluated the changes of gastrointestinal endo- crine hormones and upper gastrointestinal symptoms between PPI monotherapy group and PPI plus mosapride group.

\section{Materials and Methods}

\section{Setting and Participants}

Patients were recruited from the Gangnam Severance Hospital, Yonsei University, Korea, between September 2008 and June 2010. The study was conducted in accordance with the Declaration of Helsinki and this study protocol was approved by the Yonsei University College of Medicine Ethics Committee. Written informed consents were obtained from all patients prior to participation. The patients who were diagnosed as GERD by applying the Montreal criteria and had normal gastric emptying were included. ${ }^{18}$ Exclusion criteria included patients (1) who had organic gastrointestinal disease including inflammatory bowel disease, cancer and ulcer (2) who took drugs which could affect evaluation of the treatment; other PPIs, $\mathrm{H}_{2} \mathrm{RAs}$, prokinetics, mucosal protective agents, antacids, cholinergic and anticholinergic agents, and antidepressants for at least 4 weeks prior to study start, (3) who had severe systemic diseases including hepatic and nephrotic disease, (4) who had previous gastrectomy history, and (5) who was in state of pregnancy.

\section{Study Design and Treatment Protocol Medication protocol}

Patients in PPI monotherapy group were given pantoprazole 40 mg once daily $\left({ }^{\mathbb{R}}\right.$ Pantoloc; Pacific Pharma Co. Ltd., Seoul, Korea) and placebo tablets that were identical to mosapride citrate tablets t.i.d (3 times a day) (Daewoong Pharm Co. Ltd.,

Pantoprazole + Placebo

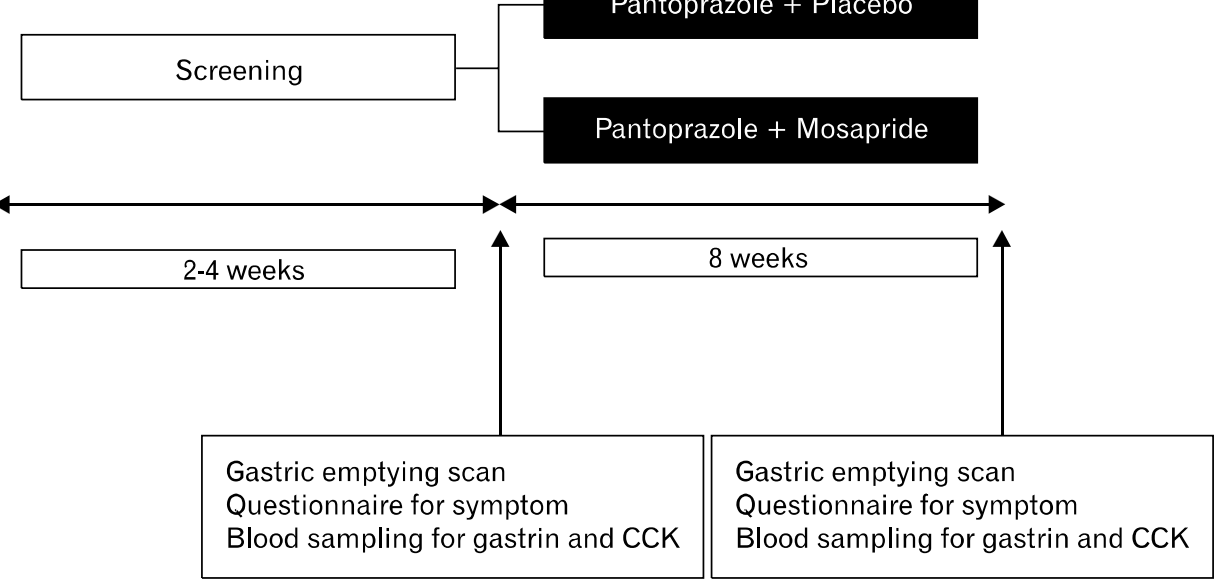

Figure 1. Study flow diagram. CCK, cholecystokinin. 
Seoul, Korea) for 8 weeks. Patients in PPI plus mosapride group were given pantoprazole $40 \mathrm{mg}$ once daily and mosapride citrate $\left({ }^{\circledR}\right.$ Gasmotin; Daewoong Pharma Co. Ltd., Seoul, Korea), 5 mg t.i.d for 8 weeks. The drugs which could affect the gastrointestinal function and gastric acid secretion were not allowed to be used throughout the study.

\section{Visit Schedule and Outcome Assessments (Fig. 1)}

This study was conducted as a prospective randomized, double-blind, placebo-controlled study. After informed consent was obtained, the screening examinations were conducted including a complete medical history, esophagogastroduodenoscopy, and blood sampling. Patients recorded questionnaires regarding gastroesophageal reflux symptoms including heartburn, acid regurgitation and dyspeptic symptoms including nausea/vomiting, belching, postprandial fullness, postprandial bloating and early satiety. The symptom severity was assessed with response options as no symptom (0), mild (1), moderate (2) or severe (3). Patients who were determined to meet all inclusion/exclusion criteria were randomized into 2 study group by PPI monotherapy group and PPI plus mosapride group, and underwent the first gastric emptying study and serum test for fasting plasma gastrin and plasma CCK.

After 8 weeks of drug treatment, all subjects visited hospital for a second gastric emptying study. Symptom scores were checked by questionnaires about gastroesophageal reflux symptoms, dyspeptic symptoms and any reported adverse events were checked in this visit. The patients who consented blood samplings were checked on the plasma gastrin and plasma CCK.

\section{Quantification of Gastric Emptying}

Gastric emptying scan was assessed by a standardized scintigraphy method. ${ }^{19,20}$ After a 12 hour fast, patients underwent scintigraphy after ingestion of the standard solid meal in the sitting position. The solid meal was consisted of $50 \mathrm{~g}$ of scrambled eggs ( $75 \mathrm{kcal})$ and $210 \mathrm{~g}$ of boiled rice $(315 \mathrm{kcal}$, Korean standard diet) which was labeled with $500 \mu \mathrm{Ci}$ of $99 \mathrm{mTc}$-pertechnate. The contents of the radioactive materials in the stomach were measured by external scintigraphy using a gamma camera with a low-energy, all-purpose, parallel-hole collimator, immediately following completion of meal and then at 30,60 and 90 minutes after the end of meal. The main parameters were half gastric emptying time ( $\mathrm{T}_{1 / 2}$, minutes) and percentage of gastric retention at 30,60 and 90 minutes. $\mathrm{T}_{1 / 2}$ was defined as the time taken to empty $50 \%$ of the gastric content.

\section{Plasma Gastrin and Cholecystokinin}

Whole blood samples $(5 \mathrm{~mL})$ were collected from patients after fasting for 12 hours. Blood samples were immediately centrifuged and then stored at $-20^{\circ} \mathrm{C}$ until the assay. Plasma gastrin- 17 level was determined by using enzyme immunoassays kit (Biohit Plc., Helsinki, Finland) and plasma CCK level was measured with enzyme immunoassays kit (Phoenix Pharmaceuticals, CA, USA) with range of $0-100 \mathrm{ng} / \mathrm{mL}$.

\section{Statistical Methods}

Demographic characteristics and individual symptom scores from baseline and follow-up visit were compared between PPI monotherapy group and PPI plus mosapride group by the student's $t$ test, or by the nonparametric Mann-Whitney $\mathrm{U}$ test if required. In addition, $T_{1 / 2}$ and residual gastric contents at 30, 60 and 90 minutes calculated by gastric emptying scan and fasting plasma gastrin $(\mathrm{pg} / \mathrm{mL})$ and CCK $(\mathrm{ng} / \mathrm{mL})$ level from baseline and follow-up visit were compared between PPI monotherapy group and PPI plus mosapride group by the student's $t$ test. Data are presented as mean \pm standard error and all efficacy analyses were based on two-sided tests, with $P \leq 0.05$ considered as significant. All analyses were performed using SPSS 12.0 (SPSS Inc., Cary, NC, USA).

\section{Results}

\section{Participant Flow and Follow-up}

Thirty-eight patients screened (mean age 50.8 years [range 20-70]; 19 males, 19 females) were randomized into the study either as PPI monotherapy group or PPI plus mosapride group in accordance with the study design (Fig. 2). Eight patients discontinued the study, and there were no statistical differences in demographic characteristics between both groups (Table).

\section{Gastric Emptying Scan}

Results of gastric emptying between pre-treatment vs posttreatment are presented in Figure 3. PPI monotherpy significantly delayed gastric emptying increasing $\mathrm{T}_{1 / 2}$ from $57.5 \pm$ 12.9 minutes to $88.5 \pm 48.2$ minutes $(P=0.023)$. The concomitant use of PPI and mosapride, showed no significant changes in gastric emptying; $\mathrm{T}_{1 / 2}$ from $61.2 \pm 17.8$ minutes to $65.0 \pm 15.5$ minutes $(P=0.536)$. 


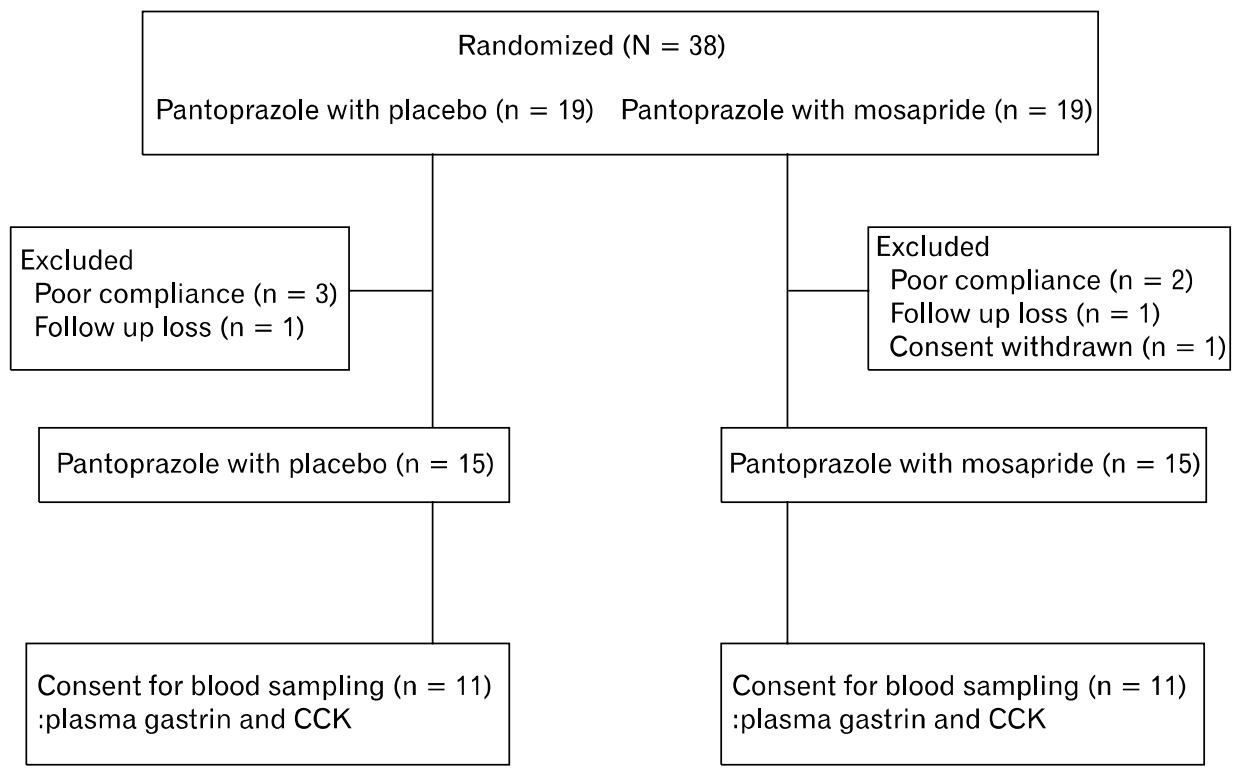

Figure 2. Flowchart of patient management in the study. CCK, cholecystokinin.

Table. Demographic Characteristics by Treatment Group

\begin{tabular}{lccc}
\hline & PPI group $(\mathrm{n}=15)$ & PPI + mosapride group $(\mathrm{n}=15)$ & $P$-value \\
\hline Age (mean age [range], yr) & $53.27(25-66)$ & $48.47(20-70)$ & 0.302 \\
Sex $(\mathrm{M}: \mathrm{F})$ & $10: 5$ & $6: 9$ & 0.153 \\
Height (mean $\pm \mathrm{SE})$ & $166.7 \pm 6.5$ & $163.7 \pm 9.7$ & 0.328 \\
Weight (mean $\pm \mathrm{SE})$ & $65.9 \pm 10.2$ & $62.2 \pm 12.9$ & 0.404
\end{tabular}

PPI, proton pump inhibitor.

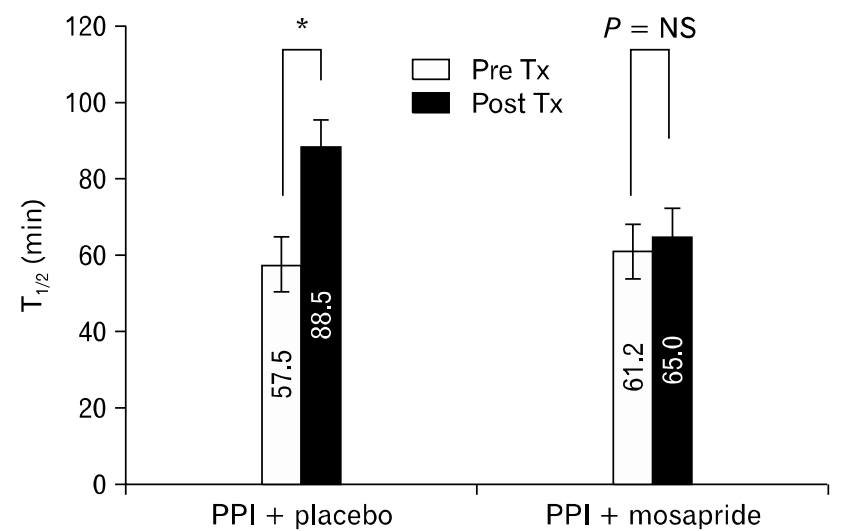

Figure 3. Effect of proton pump inhibitor (PPI) plus placebo drugs (n $=15)$ and PPI plus mosapride $(\mathrm{n}=15)$ for 8 weeks on time to gastric half-emptying $\left(\mathrm{T}_{1 / 2}\right)($ mean $\pm \mathrm{SEM}) .{ }^{*} P<0.05$.

When examined sequentially over time, PPI increased gastric retention (i.e., delayed gastric emptying) by $12.1 \pm 7.9 \%(P$ $=0.006)$ at 30 minutes, $17.9 \pm 7.6 \%(P=0.005)$ at 60 minutes, and $19.5 \pm 8.0 \%(P=0.006)$ at 90 minutes when compared with baseline (Fig. 4A). In contrast, in the group receiving PPI plus mosapride, gastric retention was not changed at 30, 60 and 90 minutes compared with baseline (Fig. 4B).

\section{Fasting Plasma Gastrin and Cholecystokinin}

Plasma gastrin levels were within normal range $(<50$ $\mathrm{pg} / \mathrm{mL}$ ) in both groups at baseline, but showed significantly higher level in PPI monotherapy group after treatment end points (46.58 pg/mL vs. $103.11 \mathrm{pg} / \mathrm{mL}, P=0.028$ ) (Fig. 5A). Plasma CCK was within normal range in baseline and there were no significant changes after treatment in both groups (Fig. 5B).

\section{Clinical Efficacy Parameters}

Gastoesophageal reflux symptoms were improved after treatment and there were no significant differences between 2 groups (Fig. 6). In the aspect of dyspeptic symptom, belching and postprandial fullness were improved in PPI monotherapy group. Nausea/vomiting and postprandial bloating additional to belching and postprandial fullness were improved in PPI plus mo- 
A

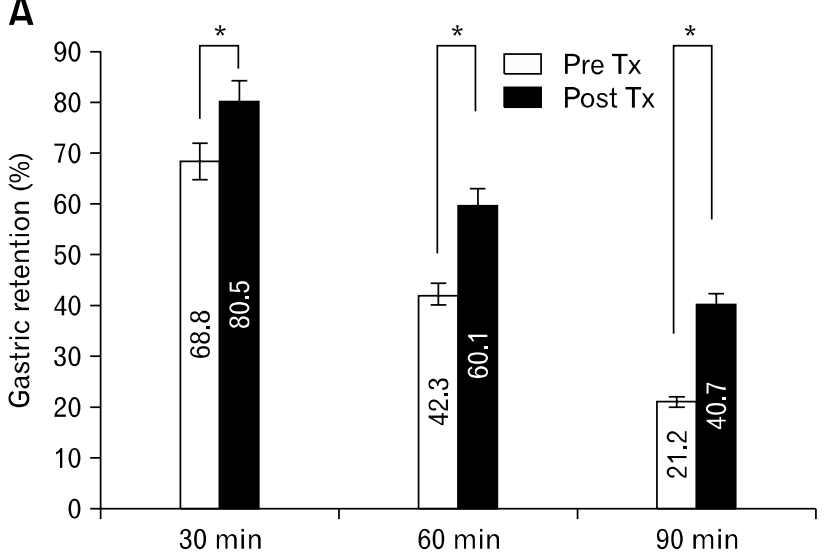

B

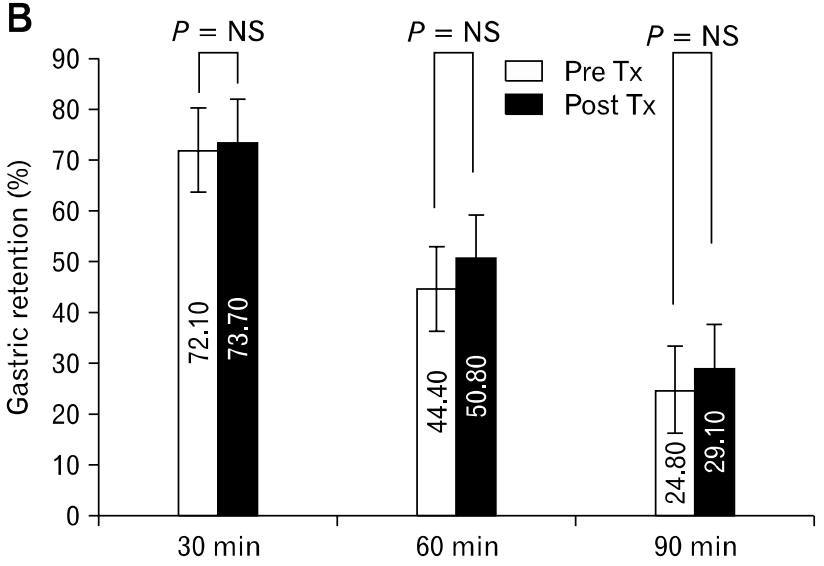

Figure 4. (A) Effect of proton pump inhibitor (PPI) plus placebo drugs $(n=15)$ for 8 weeks on percentage of gastric retention at 30,60 and 90 minutes after test meal (mean \pm SEM) and (B) PPI plus mosapride $(n=15)$ for 8 weeks on percentage of gastric retention at 30,60 and 90 minutes after test meal (mean \pm SEM.). ${ }^{*} P<0.05$.

A

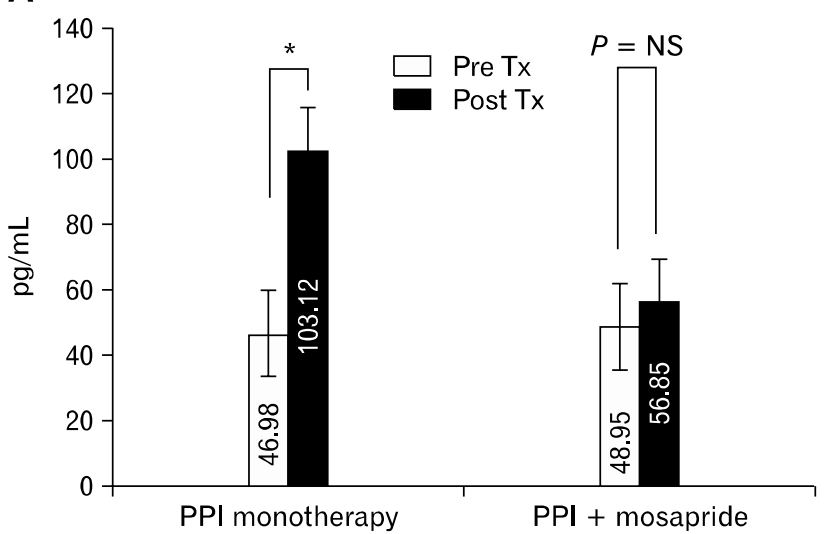

B

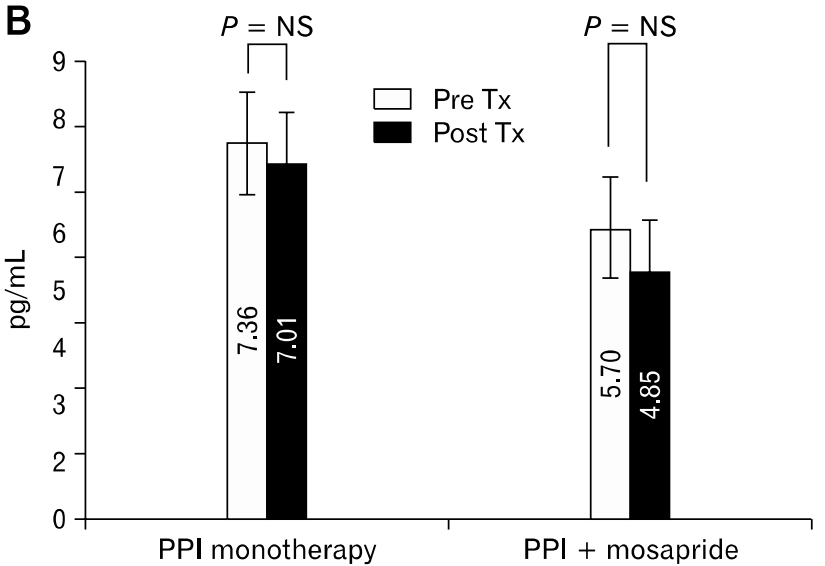

Figure 5. (A) Changes in fasting plasma gastrin level between proton pump inhibitor $(\mathrm{PPI})+$ placebo group $(\mathrm{n}=11)$ and PPI + mosapride group $(\mathrm{n}=11)$ before and after treatment $(\mathrm{B})$ Changes in fasting cholecystokinin gastrin level between PPI + placebo group $(\mathrm{n}=11)$ and PPI + mosapride group $(\mathrm{n}=11)$ before and after treatment. ${ }^{*} P<0.05$.

sapride group. Early satiety did not show significant change after treatment in both groups (Fig. 7).

\section{Adverse Events}

Neither group of volunteers reported any severe side effects or clinically significant adverse events after randomization and during drug treatment. All adverse events were mild. In PPI monotherapy group, abdominal bloating (1 occurrence) and vomiting (1 occurrence) were noted, and in PPI plus mosapride group, vomiting (2 occurrences) and abdominal pain (1 occurrence) were reported.

\section{Discussion}

The main treatment for GERD is potent acid suppression by using PPI. ${ }^{21,22}$ Adding prokinetic drugs to PPI in the treatment of GERD is recommended, due to enhancing esophageal motor function, although the efficacy is controversial. ${ }^{23-27} \mathrm{PPI}$ induced the delay of gastric emptying in solid food, but there was few literature about prevention of the treatment delayed gastric emptying, and evaluations on dyspeptic symptoms. ${ }^{8,28-30}$ Tegaserod (5-HT4 receptor agonist) was used to normalize the delayed gastric empting caused by PPIs in previous study, but tegaserod is out of market from its cardiovascular risk, so there is no proven safe 
drug which was studied for preventing the PPI induce delayed gastric emptying.

In present study, the efficacy of mosapride citrate for preventing the PPI induced gastric emptying was assessed. Mosapride citrate, a $5-\mathrm{HT}_{4}$ receptor agonist, is a prokinetic drug used in functional gastrointestinal disorder including gastroesophageal reflux disease and functional dyspepsia and is safe for it does not cause QT prolongation. ${ }^{31,32}$ The action mechanism of mosapride includes enhancement of esophageal motor function, acceleration

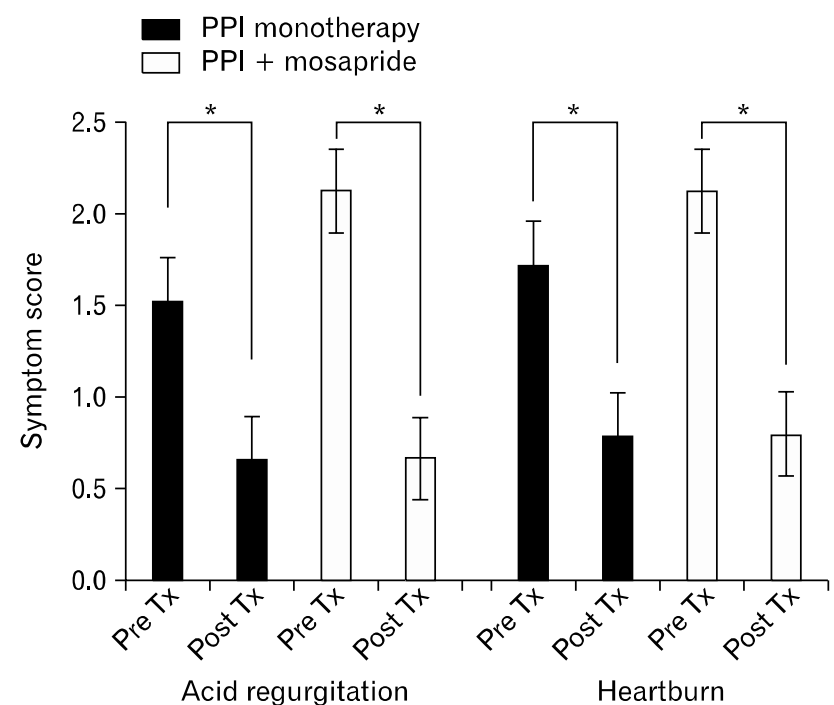

Figure 6. Changes in gastroesophageal reflux symptoms (acid regurgitation and heartburn) between the proton pump inhibitor (PPI) + placebo group $(\mathrm{n}=15)$ and the PPI + mosapride group $(\mathrm{n}=15)$ before and after treatment. ${ }^{*} P<0.05$. of gastric emptying, and enhanced acid inhibitory effect of PPIs in humans. ${ }^{23,33-35}$

In this study, PPI treatment was associated with significant delays in gastric emptying by $53.9 \%$ prolongation in $\mathrm{T}_{1 / 2} \mathrm{com}-$ pared to baseline which was slightly higher than the previous report with $15-40 \%$ delay in $\mathrm{T}_{1 / 2}$ during PPI treatment. ${ }^{5,36}$ However, with mosapride added to PPI, the delayed gastric emptying did not occurr. The delaying effect of PPI on gastric emptying appears to be manifested by the increase in percentage of meal retained at 30,60 and 90 minutes compared with pre-treatment baseline values. The observation in this study is that mosapride effectively prevented the delay in gastric emptying induced by PPI as by the prokinetic effect.

In aspect of gastrointestinal endocrine hormones, plasma gastrin level was increased in PPI monotherapy group as is known, ${ }^{15}$ but there was no significant change in PPI plus mosapride group after treatment. The mechanism for the normalization of gastrin level in PPI plus mosapride group could be as follows: emptying of solid food contents in the stomach increases by mosapride and less acid secretion for hydrolysis is needed compared to PPI monotherapy. Lowered needs for the acid secretion could inhibit the increase in the plasma gastrin level and consequently G-cell hyperplasia by the feedback mechanism. Although more study in gut hormone changes by prokinetic drug is needed, PPI plus mosapride therapy could prevent the dyspeptic symptom development after discontinuation of PPI by inhibiting increased serum gastrin level and $\mathrm{G}$ cell hyperplasia.

CCK is known to be associated with decrease of antral motility and previous studies showed that PPI induced the decrease

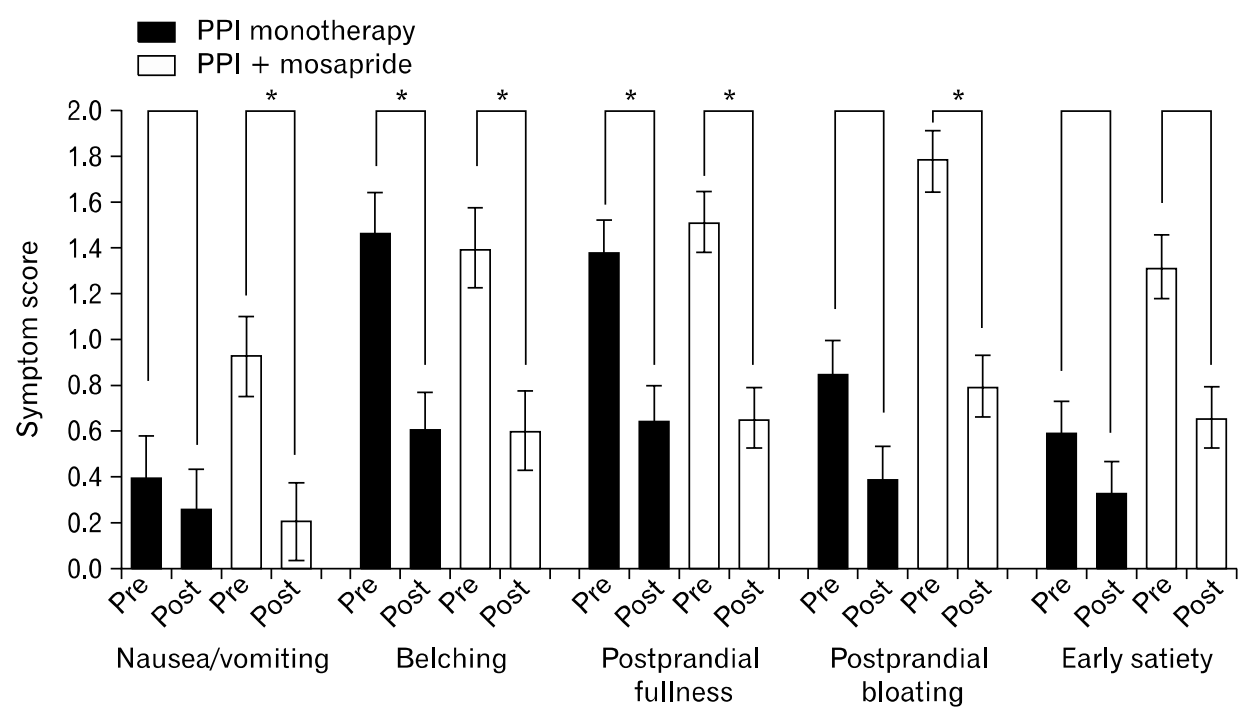

Figure 7. Changes in dyspeptic symptoms (nausea/vomiting, belching, postprandial fullness, postprandial bloating and early satiety) between the proton pump inhibitor (PPI) + placebo group $(\mathrm{n}=15)$ and the PPI + mosapride group $(\mathrm{n}=15) .{ }^{*} \mathrm{P}<0.05$. 
of plasma $\mathrm{CCK}$, but in our study there was no significant change in plasma CCK level after treatment. ${ }^{37,38}$ In addition to the fasting state in this study, complementary measurements of the postprandial CCK level would be needed to clarify the relationship between gastrointestinal symptom and plasma CCK level.

In the aspect of association of the endocrine hormone changes and delayed gastric emptying after PPI therapy, plasma gastrin is more related to regulation of gastrointestinal motility rather than plasma CCK.

In symptomatic aspects, reflux symptoms including heartburn and acid regurgitation were improved both in PPI monotherpy and PPI plus mosapride group, and there were no significant difference between both groups, as reported in previous studies. ${ }^{32}$ In dyspeptic symptoms, belching and postprandial fullness were improved in both group, but nausea and postprandial bloating symptoms were improved in PPI plus mosapride group. This could be an evidence that mosapride improved dyspeptic symptoms by additional gastroprokintic effect, but this study had a limitation because baseline symptom scores before treatment in PPI plus mosapride group was higher than PPI monotherapy. The early satiety symptom was not improved in both groups, and it could be partially explained by the unchanged CCK level which shows the control of food intake. ${ }^{39}$ Reason for the mismatching of gastric emptying and dyspeptic symptoms is that functional dyspepsia is multifactorial pathogenesis, which includes delayed gastric emptying, impaired gastric accommodation of food intake, and hypersensitivity to gastric distention.

In summary, we found that mosapride combination therapy to PPIs prevent PPI-induced delayed gastric emptying and increased plasma gastrin level, and there were mild improvements of dyspeptic symptoms. There are several limitations in our study, resulting from factors such as the small number and the characteristics of subjects (i.e., sex difference) due to dropped-out. Although larger-scale trial is needed to validate the clear benefit of mosapride in the clinical symptom improvements by preventing delayed gastric motility when using PPIs, data in this study provide evidence that PPIs plus mosapride combination therapy in GERD is able to prevent dyspeptic symptoms induced by the long-term maintenance treatment or after the discontinuation of PPIs therapy.

\section{Acknowledgements}

Estimation of gastrin and CCK level was supported by Research Center, Green Cross Corporation.

\section{References}

1. Shaheen NJ, Hansen RA, Morgan DR, et al. The burden of gastrointestinal and liver diseases, 2006. Am J Gastroenterol 2006;101: 2128-2138.

2. Locke GR 3rd, Talley NJ, Fett SL, Zinsmeister AR, Melton LJ 3rd. Prevalence and clinical spectrum of gastroesophageal reflux: a population-based study in Olmsted County, Minesota. Gastroenterology 1997;112:1448-1456.

3. Fass R. Proton pump inhibitor failure - what are the therapeutic options. Am J Gastroenterol 2009;104(suppl 2):S33-S38.

4. Fock KM, Talley NJ, Fass R, et al. Asia-Pacific consensus on the management of gastroesophageal reflux disease: update. J Gastroenterol Hepatol 2008;23:8-22.

5. Benini L, Castellani G, Bardelli E, et al. Omeprazole causes delay in gastric emptying of digestible meals. Dig Dis Sci 1996;41:469-474.

6. Parkman HP, Urbain JL, Knight LC, et al. Effect of gastric acid suppressants on human gastric motility. Gut 1998;42:243-250.

7. Rasmussen L, Qvist N, Oster-Jørgensen E, Rehfeld JF, Holst JJ, Pedersen SA. A double-blind placebo-controlled study on the effects of omeprazole on gut hormone secretion and gastric emptying rate. Scand J Gastroenterol 1997;32:900-905.

8. Cowan A, Earnest DL, Ligozio G, Rojavin MA. Omeprazole-induced slowing of gastrointestinal transit in mice can be countered with tegaserod. Eur J Pharmacol 2005;517:127-131.

9. Sanaka M, Yamamoto T, Kuyama Y. Effects of proton pump inhibitors on gastric emptying: a systematic review. Dig Dis Sci 2010;55:2431-2440.

10. Mimidis K, Tack J. Pathogenesis of dyspepsia. Dig Dis 2008;26: 194-202.

11. Tack J. Gastric motor disorders. Best Prac Res Clin Gastroenterol. 2007;21:633-644.

12. Hirako M, Kamiya T, Misu N, et al. Impaired gastric motility and its relationship to gastrointestinal symptoms in patients with chronic renal failure. J Gastroenterol 2005;40:1116-1122.

13. Kanaizumi T, Nakano H, Matsui $\mathrm{Y}$, et al. Prokinetic effect of AS-4370 on gastric emptying in healthy adults. Eur J Clin Pharmacol 1991;41:335-337.

14. Yamada M, Hongo M, Okuno Y, et al. [Effect of AS-4370 on gastric motility in patients with diabetic autonomic neuropathy.] J Smooth Muscle Res 1992;28:153-158. [Japanese]

15. Rooke $\mathrm{P}$, Baylis $\mathrm{PH}$. A new sensitive radioimmunoassay for plasma arginine vasopressin. J Immunoassay 1982;3:115-131.

16. Gutkowska J, Jankowski M, Lambert C, Mukaddam-Daher S, Zingg $\mathrm{HH}, \mathrm{McC}$ ann SM. Oxytocin releases atrial natriuretic peptide by combining with oxytocin receptors in the heart. Proc Natl Acad Sci USA 1997;94:11704-11709.

17. McCarthy DM. Adverse effects of proton pump inhibitor drugs: clues and conclusions. Curr Opin Gastroenterol 2010;26:624-631.

18. Vakil N, van Zanten SV, Kahrilas P, Dent J, Jones R; Global Consensus Group. The Montreal definition and classification of gastroesophageal reflux disease: a global evidence-based consensus. Am J Gastroenterol 2006;101:1900-1920.

19. Tougas G, Chen Y, Coates G, et al. Standardization of a simplified 
scintigraphic methodology for the assessment of gastric emptying in a multicenter setting. Am J Gastroenterol 2000;95:78-86.

20. Jung IS, Kim JH, Lee HY, Park H, Lee SI. Endoscopic evaluation of gastric emptying and effect of mosapride citrate on gastric emptying. Yonsei Med J 2010;51:33-38.

21. Wang C, Hunt RH. Medical management of gastroesophageal reflux disease. Gastroenterol Clin North Am 2008;37:879-899, ix.

22. Heidelbaugh JJ, Nostrant TT, Kim C, Van Harrison R. Management of gastroesophageal reflux disease. Am Fam Physician 2003;68: 1311-1318.

23. Ruth M, Finizia C, Cange L, Lundell L. The effect of mosapride on oesophageal motor function and acid reflux in patients with gastro-oesophageal reflux disease. Eur J Gastroenterol Hepatol 2003;15: 1115-1121.

24. Miyamoto M, Haruma K, Takeuchi K, Kuwabara M. Frequency scale for symptoms of gastroesophageal reflux disease predicts the need for addition of prokinetics to proton pump inhibitor therapy. J Gastroenterol Hepatol 2008;23:746-751.

25. Vigneri S, Termini R, Leandro G, et al. A comparison of five maintenance therapies for reflux esophagitis. N Engl J Med 1995;333: 1106-1110.

26. Miwa H, Inoue K, Ashida K, et al. Randomised clinical trial: efficacy of the addition of a prokinetic, mosapride citrate, to omeprazole in the treatment of patients with non-erosive reflux disease - a double-blind, placebo-controlled study. Aliment Pharmacol Ther 2011;33:323-332.

27. Hsu YC, Yang TH, Hsu WL, et al. Mosapride as an adjunct to lansoprazole for symptom relief of reflux oesophagitis. Br J Clin Pharmacol 2010;70:171-179.

28. Sanaka M, Yamamoto T, Kuyama Y. Effects of proton pump inhibitors on gastric emptying: a systematic review. Dig Dis Sci 2010; 55:2431-2440.

29. Tougas G, Earnest DL, Chen Y, Vanderkoy C, Rojavin M. Omeprazole delays gastric emptying in healthy volunteers: an effect prevented by tegaserod. Aliment Pharmacol Ther 2005;22:59-65.
30. Nonaka T, Kessoku T, Ogawa Y, et al. Effects of histamine-2 receptor antagonists and proton pump inhibitors on the rate of gastric emptying: a crossover study using a continuous real-time ${ }^{13} \mathrm{C}$ breath test (BreathID system). J Neurogastroenterol Motil 2011;17:287293.

31. Curran MP, Robinson DM. Mosapride in gastrointestinal disorders. Drugs 2008;68:981-991.

32. Madan K, Ahuja V, Kashyap PC, Sharma MP. Comparison of efficacy of pantoprazole alone versus pantoprazole plus mosapride in therapy of gastroesophageal reflux disease: a randomized trial. Dis Esophagus 2004;17:274-278.

33. Kamiya T, Adachi H, Hirako M, et al. Impaired gastric motility and its relationship to reflux symptoms in patients with nonerosive gastroesophageal reflux disease. J Gastroenterol 2009;44:183-189.

34. Kaneko H, Konagawa T, Kakumu S. Visceral specific analgesic action of mosapride citrate, a gastroprokinetic drug, and its metabolite against gastric distension through a $5 \mathrm{HT}_{4}$ and $\mathrm{HT}_{3}$ receptor in conscious rats. Gastroenterology 2006;2:A246.

35. Arai K, Takeuchi Y, Watanabe $\mathrm{H}$, Tsukurimichi A, Uchida N, Imawari M. Prokinetics influence the pharmacokinetics of rabeprazole. Digestion 2008;78:67-71.

36. Ji SW, Park HJ, Cho JS, Lim JH, Lee SI. Investigation into the effects of mosapride on motility of Guinea pig stomach, ileum, and colon. Yonsei Med J 2003;44:653-664.

37. Kusano M, Zai H, Shimoyama Y, et al. Rapid gastric emptying, rather than delayed gastric emptying, might provoke functional dyspepsia. J Gastroenterol Hepatol 2011;26(suppl 3):75-78.

38. Rasmussen L, Qvist N, Oster-Jørgensen E, Rehfeld JF, Holst JJ, Pedersen SA. A double-blind placebo-controlled study on the effects of omeprazole on gut hormone secretion and gastric emptying rate. Scand J Gastroenterol 1997;32:900-905.

39. Owyang C, Heldsinger A. Vagal control of satiety and hormonal regulation of appetite. J Neurogastroenterol Motil 2011;17:338-348. 